\title{
Research Program of Electric Heating in Xinjiang Area Considering Feasibility and Economy
}

\author{
Li Jianwei ${ }^{1}$, Zhang Xinyan ${ }^{2}$, Xu Jizhi ${ }^{3}$ \\ ${ }^{1}$ College of Electric Engineering, Xinjiang University, Urumchi, China \\ ${ }^{2}$ Engineering Research Center of Education Ministry for Renewable Energy Power Generation and Grid Technology, Xinjiang University, \\ Urumchi, China \\ ${ }^{3}$ College of Electric Engineering, Xinjiang University, Urumchi, China
}

Email address:

1622209843@qq.com (Li Jianwei), xjcxzxy@126.com (Zhang Xinyan), 339802968qq.com (Xu Jizhi)

To cite this article:

Li Jianwei, Zhang Xinyan, Xu Jizhi. Research Program of Electric Heating in Xinjiang Area Considering Feasibility and Economy. Journal of Electrical and Electronic Engineering. Vol. 7, No. 1, 2019, pp. 29-35. doi: 10.11648/j.jeee.20190701.14

Received: January 14, 2019; Accepted: February 27, 2019; Published: March 8, 2019

\begin{abstract}
Under the new normal economic situation, with the transformation of the national economic development mode, the main contradiction in the development of Xinjiang's power industry is that the power generation capacity does not match the social demand, and the power generation capacity is seriously excessive. According to this, Xinjiang has put forward the work plan of "electrified Xinjiang". In the field of construction, it has proposed to solve the problem of power abandonment and overcome the contradiction of power development in Xinjiang by developing electric heating schemes such as heating cables, regenerative electric boilers, heat pumps and so on. Taking the construction of the new campus of Xinjiang University as an example, this paper puts forward two feasible electric heating schemes and compares their economy, in order to promote the pace of replacing traditional energy heating with new clean energy.
\end{abstract}

Keywords: Electrification, Electric Heating, Clean Energy

\section{Introduction}

Electricity is a high-quality energy. It was not advocated in the past to convert high-quality energy into low-quality energy by electric heating. However, with the development of technology and industry, the conversion efficiency of electric heating terminal equipment is getting higher and higher [1]. Electric heating has been widely used in some pilot power in Xinjiang, and the phenomena of wind power abandonment and photoelectricity are very serious. If these thrown away energy sources are used to develop electric heating, it will play a powerful role in promoting energy conservation and emission reduction. [2]. At present, the air pollution situation in China is not optimistic. The large-scale use of fossil energy is the chief culprit of serious smog. The heating coal consumption in winter has a "contribution rate" of $16.7 \%$ for the haze environment. The spirit of the 19th National Congress of the Communist Party of China pointed out that we must further raise the awareness of environmental protection among the people, focus on building a clean, low-carbon, safe and efficient energy system, and constantly accelerate the pace of energy replacement, and promote oil-to-electricity, coal-to-electricity, and gas-to-electricity reform throughout the country., comprehensively reduce carbon emissions from energy structure and energy consumption.

In recent years, with the rapid development of power construction, the installed capacity of thermal power is increasing year by year, and the power generation of new energy is growing explosively. The contradiction between power supply and demand has been alleviated in most areas, and the phenomenon of serious abandonment of wind and light has appeared in Xinjiang. In recent years, with the continuous deepening of reform, China's energy resources are facing adjustment, which puts forward new requirements for the existing heating mode in our country, and will further promote the concept of energy-saving and environmental protection. The development and promotion of electric heating technology provides unprecedented space [3]. Liu Yang and others made a deep study on electric heating and gas heating from the perspective of environmental and 
economic benefits. After comparing the two methods, some conclusions were drawn, which provided a certain reference value for the choice of two heating modes. Sun Yong established an economic evaluation model to solve the problem of inadequate peak shaving capacity of power grid under the mode of "fixing electricity by heat" in winter heating period, and evaluated the economy of using regenerative electric heating to improve the wind power absorption scale of power grid, and pointed out the key factors affecting the economy of regenerative electric heating system. And a case study of a clean heating demonstration project under the agreed abandonment wind power price, verifying the effectiveness of the proposed economic evaluation model, and laying a theoretical foundation for the feasibility analysis of regenerative electric heating [12].

\section{Common Electric Heating Schemes}

At present, electric heating can be divided into centralized heating and decentralized heating according to the form of heating. The specific way is shown in the table [4].

Table 1. Common Electric Heating Ways.

\begin{tabular}{ll}
\hline Electric heating type & Electric heating mode \\
\hline Decentralized & Thermal Cable, Carbon Crystal, Electrothermal Film, Graphene, Small Household Boiler, Heat Pump \\
Centralized & Direct-heating electric boilers, regenerative electric boilers and heat pumps (heating area over 10,000 square meters) \\
\hline
\end{tabular}

\subsection{Electric Boiler Heating}

Electric boilers can be divided into ordinary electric boilers and regenerative electric boilers according to whether or not heat storage devices are installed.

\subsubsection{Direct Heating Electric Boiler Heating}

(1) Working Principle of Electric Boiler

Boiler is a kind of thermal equipment which uses the heat energy released by fuel combustion to transfer to the water in the container, so that the water can reach the required temperature (hot water) or a certain pressure steam. Electric boilers, which use electricity as energy, convert it into heat energy through heating devices, heating water in the boiler, so that water reaches the required temperature (hot water) or a certain pressure steam thermal equipment.

(2) Components of Electric Boilers

Electric Boiler Steel Shell; Computer Control System; Low Voltage Electrical System; Electric Heating Pipe; Inlet and Outlet Pipe and Testing Instrument, etc. Among them, the heating mode of electric boiler includes electromagnetic induction heating mode and resistance (electric heating tube) heating mode. Its function is equivalent to that of grate in coal-fired boiler or burner in gas-fired boiler. At present, the most commonly used heating method of electric boilers is electric heating tube heating. Its principle is that current generates heat through resistance. This electric heating tube has the advantages of superimposed combination, convenient disassembly and maintenance, and flexible and controllable heat generation.

\subsubsection{Regenerative Electric Boiler Heating}

(1) Working Principle of Thermoelectric Storage Boiler

Thermoelectric storage boiler is mainly based on the electric boiler, through the installation of hot water storage tank or steam accumulator, thus constituting a system with heat energy exchange and storage, and then through forced circulation or natural circulation to make the water inside the electric boiler circulate to the hot water storage tank, so that it can be converted into hot water, and complete heat energy storage [5].

\section{(2) Components of Electric Boilers}

Electric Boiler; Heat Storage Device; Heat Exchange Equipment; Circulating Water Pump; Valve; Automatic Control; Power Supply and Distribution System. The above components can be roughly divided into three parts: heating system, regenerative system and exothermic system. Each of the three systems has its own functions. The regenerative system stores the heat energy converted from electric energy in the heating system and supplies heat exchange equipment through the exothermic system. Among them, the common means of heat storage are water thermal storage device, which uses water as medium for water thermal storage; the second is phase change thermal storage device, which uses high temperature phase change material as medium for phase change thermal storage. Considering economy, water is generally used as medium for heat storage in China.

(3) Advantages of regenerative boilers

The heat storage electric boiler uses electricity as a heat source, especially at night, using low-cost low-valley electricity for heating and heat storage. This operation mode can play a certain peak-shaving effect on the power supply of the power grid, and can increase the power load of the power grid at night. Increasing the number of hours of wind power nights on the Internet will help balance the power load and alleviate the contradiction of power supply, so as to save fossil energy consumption, reduce environmental pollution, and reduce urban harmful gas emissions [6].

\subsection{Heat Pump Heating}

Publicly speaking, heat pump system is the "porter" of energy. It is a kind of heat lifting device that uses high potential energy to convert low-level heat energy (such as air, soil, water) which can not be directly used in low-temperature environment medium into high-level heat energy which can be used. Its heat production is the sum of consuming high-level heat energy and absorbing heat from low-temperature environment. The use of heat pump for building heating can save part of high potential energy (such as coal, gas, oil, electricity, etc.) and effectively avoid the waste of fossil energy and other resources [7]. 


\subsection{Electric Heater Heating}

Electric heater is a heating equipment which uses electricity as energy to heat, and it can also be called electric heater. According to the different forms of heating, electric heaters can be divided into two categories: regenerative type and non-regenerative type. The working principle of the electric heater is very similar, but its heater is slightly different. At present, the common heaters are heat conducting oil, electric heating wire, ceramic, quartz tube, halogen tube and carbon fiber heater. The heating principle of regenerative electric heater is the same as that of ordinary electric heater. The difference is that the regenerative electric heater can use the low-cost electric energy in the low-trough period of the night power grid to store the heat in the special magnetic regenerative brick while using the heat-resisting and low-conductivity material outside the regenerator for thermal insulation [8].

\subsection{Heating Cable and Film}

Electrothermal film and heating cable are widely used because of their high indoor thermal comfort, high electrothermal conversion rate and easy control. The heating system can flexibly adjust the indoor temperature according to the characteristics of different building heat load and human activities in different building functional zones. It can not only realize human subjective initiative, but also use behavior energy saving to avoid waste of resources and save operation costs. Electric heating film and heating cable transmit heat by radiation. Compared with the convective heat transfer chamber under the same thermal comfort conditions, the temperature can be reduced by 3-5 C, which has certain energy saving properties. Its energy-saving principle is as follows: radiation heating can offset part of the radiation heat dissipation used by human body to balance body temperature. In order to maintain the body heat balance, it is necessary to reduce the ambient temperature to increase the difference between human body and air temperature, and then increase the convective heat dissipation [9].

\section{Economic Analysis of Electric Heating}

\subsection{Annual Cost Value Method}

In order to facilitate the cost comparison and analysis in the life cycle of heating system, the annual cost method is used to compare and evaluate the economy of various electric heating modes, which provides a basis for the selection of electric heating system in Xinjiang. The annual cost method is a dynamic comparison method based on the principle of time value of funds. The initial investment value of each scheme is converted into an annual value similar to the operating cost by using the coefficient of investment effect, and then added to the annual operating cost. The optimal scheme is the minimum one. The calculation formula of annual cost method is as follows:

$$
A C_{j}=\frac{i \times(1+i)^{n_{j}}}{(1+i)^{n_{j}}-1} \times K_{j}
$$

In the formula, $\mathrm{AC}_{\mathrm{j}}$ is the annual cost value of heating facility $j ; n_{j}$ is the service life of heating facility $j$; $i$ is the rate of return on investment, the standard discount rate within the Department is $8 \% ; K_{j}$ is the initial investment for heating facility $j$.

\subsection{Investment in Infrastructure}

Initial investment of heating system should include outdoor heating equipment investment, heating pipe network investment and user's indoor heating equipment investment. The investment of outdoor heating equipment includes the investment of boiler room, boiler and auxiliary equipment; the investment of heating pipe network includes the cost of intermediate heat exchange station, pipe network material and construction; and the investment of indoor heating equipment includes the cost of indoor heating system material, construction and various indoor heat dissipation terminal equipment. The formulas for calculating the initial investment of the system are as follows:

$$
\mathrm{K}=K_{1}+K_{2}+K_{3}
$$

\subsection{Cost of System Operation}

\subsubsection{Fuel Fee}

That is to say, the fuel cost that must be consumed to maintain the heating demand during the whole heating period is calculated by the following formula:

$$
\mathrm{A}=\mathrm{B} \times \mathrm{J}=\frac{\sum Q}{\eta Q_{d w}^{y}} \times \mathrm{J}
$$

In the formula, $\mathrm{B}$ is fuel consumption; $\mathrm{J}$ is fuel unit price; $\eta$ is boiler and heat network efficiency; $Q_{d w}^{y}$ is low calorific value of fuel; $\Sigma Q$ means that heating period needs heat supply. Among them, the formula for calculating the total heat consumption in heating season is as follows:

$$
\sum Q=Q_{n} \times \frac{t_{n}-t_{p j}}{t_{n}-t_{w}}
$$

In the formula, $Q_{n}$ is the heating design heat load; $t_{n}$ is the indoor calculating temperature in heating period; $t_{p j}$ is the average outdoor temperature in heating period; $t_{w}$ is the outdoor calculating temperature in heating period; $n$ is the days in heating period.

\subsubsection{Electricity Charges}

Electric heating project direct trading transmission and distribution price to implement electricity price policy when flat electricity and valley electricity distribution. The period of low power consumption is 12 hours (23:00-9:00; 14:00-16:00); the remaining period is 12 hours.

For the determination of operating electricity charge, only the calculation of the boiler system is needed. Boiler operation includes all kinds of water pumps, fans, coal feeding system, slag removal system, operation power consumption of boiler grate, etc. Referring to the Manual of 
Central Heating, the operating electricity charges of each heating system can be calculated by incorporating the data in the specification into the following formulas. The formulas for determining the operating electricity charges of boiler rooms are as follows:

$$
\begin{aligned}
W_{z h} & =24 N_{h} N_{t h} K_{h} \\
\mathrm{E} & =\mathrm{W}_{\mathrm{zh}} \times \mathrm{I}
\end{aligned}
$$

In the formula, $\mathrm{W}_{\mathrm{zh}}$ is the power consumption of each equipment; $\mathrm{N}_{\mathrm{h}}$ is the power consumption of each equipment; $\mathrm{N}_{\mathrm{th}}$ is the total days of heating period; $\mathrm{K}_{\mathrm{h}}$ is the coefficient of use of each equipment; $\mathrm{E}$ is the operating electricity cost; I is the price.

\subsection{Other Costs}

In electric heating, besides labor and maintenance costs, it is difficult to make accurate estimates. Generally, it includes various taxes of heating enterprises, smoke and dust discharge fees of coal-fired boiler rooms, water treatment fees, management fees, insurance fees, office expenses, travel expenses and scientific research fees. Based on reference [10], this paper chooses $2.25 \%$ of fixed assets.

\section{Electric Heating Scheme for New Campus of Xinjiang University}

The new campus of Xinjiang University is located in the east of Shuimogou District, Urumqi City. It extends east to the west of Planning University Road, south to Planning Huaguang Street, West to Planning Road, north to Planning Suzhou Road, and west to Xuelian Mountain. The land area is 260.3 hectares.

\subsection{Heating Prediction}

\subsubsection{Heating Area and Heating Load}

At present, the total heating area of Xinjiang university New Campus is about 790,000 square meters (including 100,000 reserved area). The comprehensive heat index of heating area is $80 \mathrm{w} / \mathrm{m}^{2}$, and the total heating load is about 63MW. 1 \# central heating boiler room: heating area is about 393375 square meters (reserved building area is 80,000 square meters in 1 \# heating area); heating area is about 47 3375 square meters, heating load is about 37.87 MW. 2 \# central heating boiler room: heating area is about 293525 square meters (reserved building area is 20,000 square meters in 2 \# heating area); heating area is about 313525 square meters, heating load is about $25.13 \mathrm{MW}$.

\subsubsection{Heat Source}

1 \# Boiler room is equipped with electrode hot water boiler or gas hot water boiler and matching water treatment and low-pressure distribution equipment; 2 \# Boiler room is equipped with electrode hot water boiler or gas hot water boiler and matching water treatment and low-pressure distribution equipment.

\subsubsection{Pipe Network}

The heating pipe network is laid directly, and the district central heating boiler covers the corresponding district heating area.

\subsubsection{Heat Exchange Station}

Nine heat exchanger stations are planned and constructed within the heating area.

\subsection{Secheme Selction}

\subsubsection{Programme I}

In the planned two boiler rooms, high temperature hot water boilers with electrodes, hot water storage tanks and ancillary facilities are installed respectively. Electric boilers are opened to store heat for regenerator during valley power period, and regenerator is heated for campus during peak-level power period. Five $8 \mathrm{MW}$ electrode hot water boilers and six vertical cylindrical water tanks (with a single capacity of $1000 \mathrm{~m}^{3}$ ) are installed in No. 1 boiler room. Four 6MW electrode hot water boilers, one 4MW electrode hot water boilers and four vertical cylindrical water tanks $\left(1000 \mathrm{~m}^{3}\right)$ are installed in the 2 \# boiler room. The process flow is shown in Figure 1.

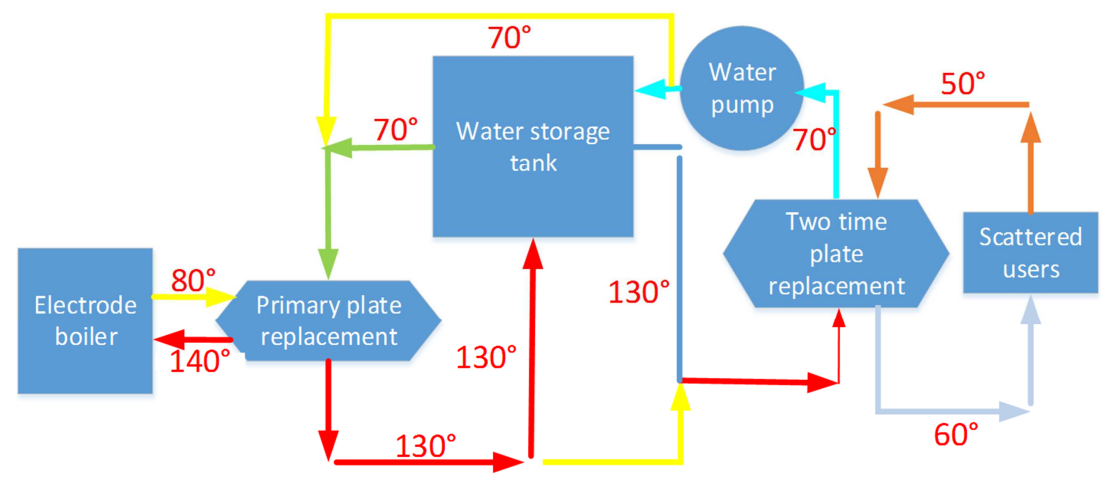

Figure 1. Schemes I Process Flow Chart.

1 \# boiler room heating equipment and its investment budget are as follows: (1) There are five electrode boilers with boiler control cabinets, the equipment type is CEJS-900
(USA), rated power is $8 \mathrm{MW}$, unit price is 4545000.0 yuan, total price is 22725000.0 yuan; (2) 6 atmospheric pressure vertical cylindrical water heaters, single $\mathrm{V}=1000 \mathrm{~m}^{3}$, 
diameter $\mathrm{D}=11.5$ meters, height $\mathrm{H}=12.0$ meters, with base insulation. The unit price is 1350000.0 yuan, the total price is 8100000.0 yuan; (3) plate heat exchanger, pure water equipment, softening water equipment, circulating water pump, frequency conversion control cabinet and pipeline system and other ancillary equipment, the total price is 1872654.0 yuan; (4) freight and commissioning fee is 164793.0 yuan; (5) equipment installation fee and management fee are estimated to be 2546807.0 yuan; (6) tax fee, the total price is 1797746.0 yuan. (7) The cost of project investment is 37207000.0 yuan.

The total cost of the project is 37207000.00 yuan.

2 \# boiler room heating equipment and its investment budget are as follows: (1) four electrode boilers with boiler control cabinet, the equipment model of CEJS-900 (USA), rated power of $6 \mathrm{MW}$, unit price of 4045000.0 yuan, total price of 1618000.0 yuan; (2) one electrode boiler with boiler control cabinet, equipment model For CEJS-900 (USA), rated power is $4 \mathrm{MW}$, unit price is $4045,000.0$ yuan, total price is 4045000.0 yuan; (3) 4 atmospheric vertical cylindrical water heaters, single $\mathrm{V}=1,000 \mathrm{~m}^{3}$, diameter $\mathrm{D}=$ 11.5 meters, height $\mathrm{H}=12.0$ meters, including base insulation. The unit price is 1350000.0 yuan, the total price is 5400000.0 yuan; (3) plate heat exchanger, pure water equipment, softening water equipment, circulating water pump, frequency conversion control cabinet and pipeline system and other ancillary equipment, the total price is 1872653.0 yuan; (4) freight and commissioning fee is 164793.0 yuan; (5) equipment installation fee and management fee is estimated to be 254607.0 yuan; (6) tax fee, the total price is 1797746.0 yuan. (7) The investment cost of the project is 32007000.00 yuan.

The total cost of the project is 32007000.0 yuan.

The total investment of $1 \#$ boiler room and $2 \#$ boiler room equipment is 69214000 yuan. This investment does not include the civil part of the boiler room. Because the construction form of the boiler room is uncertain, the investment ratio of the above-ground boiler room to the underground boiler room is about 2:1.

\subsubsection{Programme II}

In the planned two boiler rooms, gas hot water boilers and electrode high temperature hot water boilers and ancillary facilities are installed respectively. Gas-fired boilers are opened at peak and peak hours, while electric boilers are opened at Valley hours. Installation of two 10MW electrode hot water boilers and two 10MW gas hot water boilers in 1 \# boiler room. Install $27 \mathrm{MW}$ electrode hot water boilers and 2 $7 \mathrm{MW}$ gas hot water boilers in 2 \# boiler room. The process flow of the scheme is shown in Figure 2.

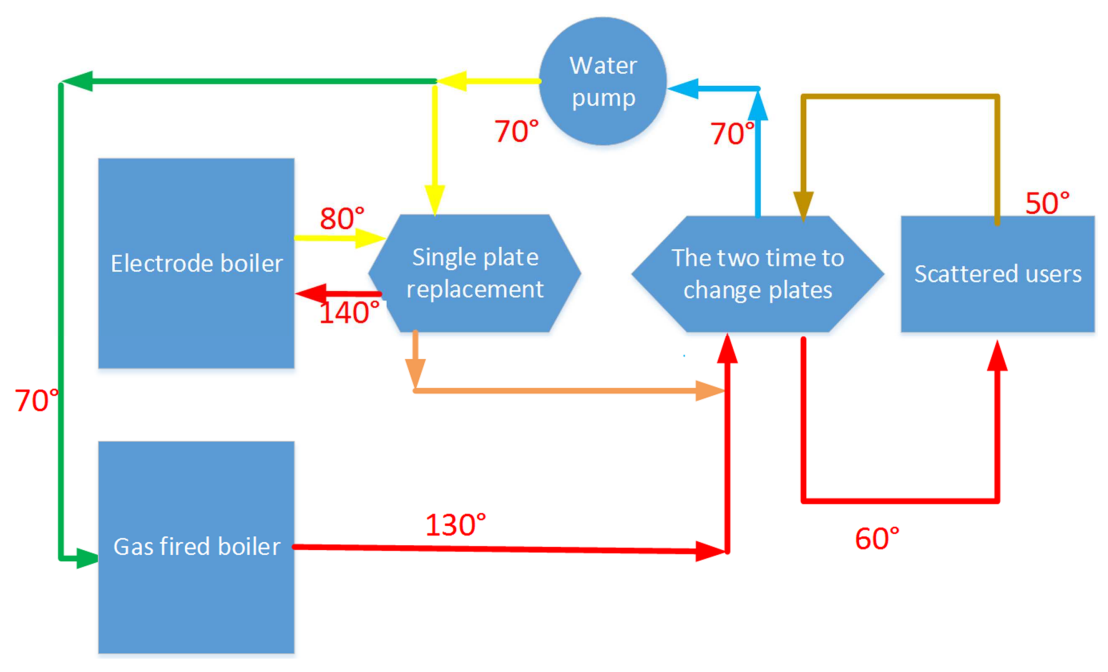

Figure 2. Schemes II Process Flow Chart.

1 \# boiler room heating equipment and investment budget of boiler room are as follows: (1) 2 electric boilers with boiler control cabinet, CEJS-900 (USA), rated power of $8 \mathrm{MW}$, unit price of 7545000.0 yuan, total price of 1509000.0 yuan; (2) 2 gas boilers with rated power of $10 \mathrm{MW}$, unit price of 150000.0 yuan, total price of 300000.0 yuan (USA). The total price of plate heat exchanger, pure water equipment, softening water equipment, circulating water pump, frequency conversion control cabinet and pipeline system is 1872654.0 yuan; (4) the total cost of transportation and commissioning is 164793.0 yuan; (5) the estimated total cost of equipment installation and management is 2546807.0 yuan; (6) tax, the total price is 179746.0 yuan; (7) the project investment cost is 24472000.0 yuan. The total cost of the project is 24472000.00 yuan.

2 \# boiler room heating equipment and its investment budget are as follows: (1) 2 electric boilers with boiler control cabinet, $3000 \times 2500 \times 5700$ long $\times$ wide $\times$ high, CEJS-900 (United States), rated power of $7 \mathrm{MW}$, unit price of 4345000.0 yuan, total price of 8680000.0 yuan; (2) 2 gas boilers with rated power of $7 \mathrm{MW}$, unit price of 1000000.0 yuan, total price of 2000000.0 yuan; 3) Plate heat exchanger, pure water equipment, softening water equipment, circulating water pump, frequency conversion control cabinet and pipeline system and other ancillary equipment, the total price is 1872654.0 yuan; (4) the total cost of freight and commissioning is 164793.0 yuan; (5) the estimated total cost of equipment installation and management is 2546807.0 yuan; 
(6) taxes, the total price is 1797746.0 yuan; (7) the project investment cost is 17062000.00 yuan. The total cost of the project is 17062000.0 yuan.

The total investment of $1 \#$ boiler room and $2 \#$ boiler room equipment is 41534,000 yuan. This investment does not include the civil part of the boiler room. Because the construction terrain of the boiler room is uncertain, the investment ratio of the above-ground boiler room to the underground boiler room is about $2: 1$.

In terms of layout, we mainly follow three principles: first, to implement the principle of saving land; The second is to consider the principle of environmental protection from the perspective of pollution, and the third is to consider the principle of economic rationality. 1 . In order to alleviate the pollution of the heat source plant to the adjacent site environment, the buildings and structures such as boiler room, fan room, transformer and distribution room are centralized in the underground layout, and the adverse effects of the heat source plant on the surrounding environment such as vision, noise and so on are alleviated through greening measures. 2 . In order to maximize the use of the campus land and avoid inconsistent with the campus building style, the gas-fired boilers and hot-water electrodes boilers constructed in this project all use underground space.

\subsubsection{Scheme Analysis}

The economic data analysis of electric heating for the two schemes is shown in tables 2 and 3.

Table 2. Programme I Analysis.

\begin{tabular}{llllll}
\hline $\begin{array}{l}\text { heating area } \\
(\mathbf{1 0 , 0 0 0} \text { square } \\
\text { meters) }\end{array}$ & $\begin{array}{l}\text { Heating load } \\
\text { (MW) }\end{array}$ & $\begin{array}{l}\text { 1kwh Electricity } \\
\text { Heating }(\mathbf{M J} / \mathbf{k w h})\end{array}$ & $\begin{array}{l}\text { annual heating } \\
\text { electricity } \\
\text { consumption (kwh) }\end{array}$ & $\begin{array}{l}\text { Electricity } \\
\text { price } \\
\text { (yuan/kwh) }\end{array}$ & $\begin{array}{l}\text { Annual } \\
\text { Electricity Cost } \\
(\mathbf{y u a n})\end{array}$ \\
\hline 79 & 63 & 3.6 & 175500000.99 & 0.114 & $\begin{array}{l}\text { Unit heating } \\
\text { area cost } \\
\left(\mathbf{y u a n} / \mathbf{m}^{\mathbf{2}}\right)\end{array}$ \\
\hline
\end{tabular}

Table 3. Programme II Analysis.

\begin{tabular}{|c|c|c|c|c|c|c|}
\hline $\begin{array}{l}\text { Natural gas price } \\
\text { (yuan/M3 }\end{array}$ & $\begin{array}{l}\text { heating area } \\
(10,000 \text { square } \\
\text { meters })\end{array}$ & $\begin{array}{l}\text { Heating load } \\
\text { (MW) }\end{array}$ & $\begin{array}{l}\text { 1kwh Electricity } \\
\text { Heating } \\
(\mathrm{MJ} / \mathrm{kwh}) \\
\end{array}$ & $\begin{array}{l}\text { annual heating } \\
\text { electricity } \\
\text { consumption (kwh) }\end{array}$ & $\begin{array}{l}\text { Electricity } \\
\text { price } \\
\text { (yuan/kwh) }\end{array}$ & $\begin{array}{l}\text { Unit heating area } \\
\text { cost }\left(\text { yuan } / \mathbf{m}^{2}\right)\end{array}$ \\
\hline 0.37 & 79 & 63 & 3.6 & 175500000.99 & 0.114 & 25.12 \\
\hline
\end{tabular}

\subsubsection{Scheme Selection}

Table 4. Selection of Programmes.

\begin{tabular}{lll}
\hline Name & Scheme 1 & Scheme 2 \\
\hline Initial investment & High & Law \\
Operation mode & Heat storage + direct heat & "Gas-electricity Complementarity" \\
Air consumption & Law & High \\
running cost & Law & High \\
Risk & High & Law \\
Regulatory nature & Relatively easy & Easy \\
Reserve nature & Relatively high & High \\
Power consumption & High & Law \\
\hline
\end{tabular}

Through analysis and comparison, according to the factors of investment economy, stable operation, safety management and convenient maintenance of heating schemes, it is suggested to adopt the second scheme to heat the new campus of Xinjiang University. That is the form of "gas-electricity complementary" heating, which can effectively utilize the price of grain electricity and achieve the bidirectional complementarity of new energy [11].

\section{Conclusion}

This paper gives a brief introduction to the current electric heating mode, and takes the new campus of Xinjiang University as an example to analyze the feasibility and economy of electric heating, and puts forward a scheme of electric heating. Because the school has the functions of business, teaching, office and living zones, it is widely representative. In conclusion, the electric heating system can be fully qualified for heating work in Xinjiang in terms of economy, thermal comfort, energy efficiency and environmental benefits.

In Xinjiang, the use of electric heating is of great significance: in line with national and local policies, to achieve electricity substitution; in winter, the use of wind power instead of coal-fired and gas-fired boilers for urban heating can increase the regional electricity load, improve the local wind power absorption capacity, and reduce the pressure of power grid outgoing, especially in the period of low power load at night, wind power is used for urban heating, from demand. Starting from the side, it reduces the difficulty of peak regulation and absorption of wind power, and has important significance for the sustainable development of wind power. Urumqi is located in the cold region of Northwest China, with a long heating period and consumes a lot of coal and natural gas resources. The use of clean electricity to meet urban heating needs can reduce the pressure of heating subsidies brought by the rising prices of coal and natural gas to local governments; the use of "gas-electricity complementary" heating mode can reduce operating costs; after the completion of the transformation, 
the emission of air pollutants can be reduced.

Although there are many shortcomings in the content of this thesis, there are many factors that have not been considered. However, the author firmly believes that with the deepening of the follow-up research, the research will be more perfect and will certainly play a certain role in the national electric energy substitution project. The guiding role plays a certain role in promoting the "electrification" process in Xinjiang and provides an important theoretical basis for the transformation of energy use structure and sustainable development in Xinjiang.

\section{Acknowledgements}

This research was financially supported by National Natural Science Foundation of China (Grant No. 51667018).

\section{References}

[1] Li Lixin. Electric power substitution should rise to national strategy [N]. China Electric Power Daily, 2014-03-06 (004).

[2] Chen Bo. Brief analysis of the development prospects of wind power heating in Xinjiang [J]. Building materials and decoration, 2017 (25): 179.

[3] Liu Yang, Ran Chunyu. A comparative study of electric heating and gas heating $[\mathrm{J}]$. Journal of Chifeng University (Natural Science Edition), 2016, 32 (22): 171-173.

[4] Chen Haoli. Study on selection and benefit analysis of electric heating scheme in Kuitun City [D]. North China Electric Power University, 2015.

[5] Gong Jianguo. Discussion on the application of water-storage thermoelectric boilers as heating sources for small and medium-sized buildings $[\mathrm{J}]$. Enterprise Technology Development, 2013, 32 (11): 21-22.

[6] Tangshan, Yi Jun. Heat supply system of regenerative boiler and its technical and economic application [J]. Engineering technology research, 2017 (11): 111-112.

[7] Chenna, Tang Yuanming. Application Research of Environmental Protection and Energy Saving Ground Source Heat Pump Technology [J]. Environmental Protection and Circular Economy, 2008 (12): 34-37.

[8] Li Deying. Heating Engineering [M]. Beijing: China Construction Industry Press, 2004.

[9] Long Weiding, Wuyong. Building Energy Saving Technology [M]. Beijing: China Construction Industry Press, 2009.

[10] He Mengchun. Economic comparison of different heating modes for residential buildings in central heating areas $[\mathrm{J}]$. Energy-saving technology, 2008 (04): 340-346.

[11] Zhang Jian, Wu Liang, Yuan Xinrun. Application analysis of decentralized electric heating in Tianjin [J]. DSM, 2015, 17 (06): 33-36.

[12] Sun Yong, Yan Gangui, Zheng Taiyi, Fengke, Yang Guoxin, Li Junhui, Wang Zongbao. Economic analysis of wind abandonment in regenerative electric heating under the background of power market [J]. Energy Storage Science and technology, 2016, 5 (04): 532-538. 